DOI: http://dx.doi.org/10.18203/2320-1770.ijrcog20173452

\title{
CT scan findings in patients of eclampsia
}

\author{
Barkha Gurjar*, R. P. Rawat
}

Department of Obstetrics and Gynecology, Government Medical College, Kota, Rajasthan, India

Received: 17 May 2017

Revised: 26 May 2017

Accepted: 17 June 2017

\section{*Correspondence:}

Dr. Barkha Gurjar,

E-mail: barkhagurjar1986@gmail.com

Copyright: ( $)$ the author(s), publisher and licensee Medip Academy. This is an open-access article distributed under the terms of the Creative Commons Attribution Non-Commercial License, which permits unrestricted non-commercial use, distribution, and reproduction in any medium, provided the original work is properly cited.

\section{ABSTRACT}

Background: Eclampsia is defined as the occurrence of one or more convulsions in association with raised blood pressure and proteinuria in a pregnant or puerperal woman, usually between 20 weeks' gestation and the first 48 hours postpartum. Maternal mortality in India due to eclampsia is 2 to $30 \%$ and perinatal mortality is 30 to $50 \%$. Abnormal findings on neuroimaging have been noted in as many as $80-90 \%$ of women with eclampsia. Most common lesions are seen in parieto-occipital lobes in the distribution of posterior cerebral arteries. This lesion occurs as a result of vasogenic oedema induced by endothelial damage and other changes contributing to pathophysiology of eclampsia. Objectives of present work were to study involvement of different areas of brain in eclampsia and to study maternal and fetal outcomes.

Methods: This is a prospective study done over a period of 6 months the study population were chosen by random sampling who were eclampsia patients admitted trough emergency and also indoor patients who develop eclampsia after admission. Total 12 patients were analyzed. CT scan of brain performed after confinement of fetus and after stabilising the mother. Maternal and fetal outcomes were observed in these cases.

Results: $58.33 \%$ (7cases) eclamptic mothers were primigravida and 41.66\% (5 cases) were multigravida. Among them $16.66 \%$ ( 2 cases) had postpartum eclampsia while $83.33 \%$ (10 cases) had antepartum eclampsia. $75 \%$ mothers delivered by vaginal route and 25\% mothers undergone LSCS. There were 14 births including 2 twin deliveries, out which 12 were live births and 2 Intra uterine deaths. On CT Scan- Brain stem edema was seen in 9 cases, infarction in 1 case, hemorrhage in 1 case and in 1 case CT was normal. Most common lobe involved is parietal (10 cases) followed by occipital ( 7 cases), frontal (4 cases), temporal (3 cases).

Conclusions: Early recognition of the disorder and prompt management by control of blood pressure, removal of the offending medications or treatment of associated diseases is essential to prevent irreversible brain damage. CT scan of brain in eclampsia can provide useful intra cerebral information and should be done in cases with severe neurologic manifestations, if possible for every eclamptic mother.

Keywords: CT Scan, Eclampsia, Eclamptic mother, Postpartum eclampsia

\section{INTRODUCTION}

Eclampsia is defined as the occurrence of one or more convulsions in association with raised blood pressure and proteinuria in a pregnant or puerperal woman, usually between 20 weeks' gestation and the first 48 hours postpartum. ${ }^{1}$ In contrast, late postpartum encephalopathy (LPE) occurs between 48 hours and 1 month postpartum, frequently in women who have had a normal pregnancy and delivery and have no signs of a preeclamptic syndrome. ${ }^{1,2}$ Hospital incidence in India is between 1 in 500 to 1 in 30 . It occurs more commonly in 
primigravidae, nearly $75 \%$ of all eclampsia. $50 \%$ of eclampsia are seen from 36 weeks of gestation to term. Convulsions in eclampsia occur $50 \%$ in antenatal period, $30 \%$ intrapartum, $20 \%$ in postpartum period. Maternal mortality in India due to eclampsia is 2 to $30 \%$ and perinatal mortality is 30 to $50 \% .^{3}$

Cerebral complications are the major cause of deaths in eclampsia. Cerebral complications have no permanent neurologic deficits, and there is evidence which suggests that the neuropathophysiology of eclampsia may be related to changes in cerebral blood flow. Proposed mechanisms include hypertensive encephalopathy, cerebral vasospasm, cerebral edema and petechial hemorrhage. Abnormal findings on neuroimaging have been noted in as many as $80-90 \%$ of women with eclampsia.

Most common lesions are seen in parieto-occipital lobes in the distribution of posterior cerebral arteries. This lesion occurs as a result of vasogenic oedema induced by endothelial damage and other changes contributing to pathophysiology of eclampsia. ${ }^{4}$

Imaging is interesting for a better understanding of the pathophysiology of eclampsia, but in the clinical practice, the decision to perform CT or MR imaging should be more restrictive. Patients presenting with history of uncomplicated eclampsia, without focal neurological deficit should not be investigated by these techniques.

Patients with focal neurologic deficit, or signs of mass effect, or decrease in the level of consciousness should undergo CT scan as a first choice, in order to exclude haemorrhagic lesions or other major complications. Cerebral CT may be normal or may reveal transient white matter hypodensities.

Occasionally, haemorrhagic lesions can be found in more severe forms. Goal of CT scan was to define abnormalities that may be treated and decreases the morbidity and mortality associated with the condition.

\section{METHODS}

Patients admitted at our institution with fits were observed in order to study involvement of different areas of brain in CT scan over a period of 6 months. The study population were chosen by random sampling who were eclampsia patients admitted through emergency and also indoor patients who develop eclampsia after admission. Maternal and fetal outcomes were observed in these cases.

\section{Inclusion criteria}

Patients with eclampsia (atleast one episode of seizure in women with more than 20 weeks gestation or less than 06 weeks postpartum with blood pressure more than $140 \mathrm{~mm}$ of $\mathrm{Hg}$ systolic and $90 \mathrm{~mm}$ of $\mathrm{Hg}$ diastolic with urine albumin of more than $0.3 \mathrm{gm} / \mathrm{L}$ ).

\section{Exclusion criteria}

- Women who were known case of epilepsy.

- Seizures due to metabolic disturbances, space occupying lesions, intracerebral infections, poisoning or trauma.

Total 12 patients were chosen according to inclusion criteria. Basic information including age, parity, gestational age, previous medical or obstetric history was taken. Detailed history of convulsion like duration, time, number of convulsion and premonitory symptoms were sought.

Basic investigations like urine albumin (by dipstick) are measured, complete hemogram, platelet count, serum uric acid, serum creatinine, liver enzymes were sent. Standard $\mathrm{MgSO}_{4}$ protocol was given. If patient was undelivered, assessment of cervix and delivery of fetus done accordingly either by induction of labour or caesarian section. CT scan perfomed after confinement of fetus and after stabilising the mother.

\section{RESULTS}

Total 12 patients were included in this study. $58.33 \%$ (7cases) eclamptic mothers were primigravida and $41.66 \%$ (5 cases) were multigravida. Among them $16.66 \%$ ( 2 cases) had postpartum eclampsia while $83.33 \%$ (10 cases) had antepartum eclampsia. $75 \%$ mothers delivered by vaginal route and $25 \%$ mothers undergone LSCS. There were 14 births including 2 twin deliveries, out which 12 were live births and 2 Intra uterine deaths.

On CT Scan- Brain stem edema was seen in 9 cases, infarction in 1case, hemorrhage in 1case and in 1 case CT was normal. Most common lobe involved is parietal (in 10 cases) followed by occipital ( 7 cases), frontal (4 cases), temporal (3 cases).

Table 1: Distribution of lesions as seen on CT scan.

\begin{tabular}{|ll|}
\hline Lesion & Number of patients \\
\hline Hypodense & $9(75 \%)$ \\
\hline Infarction & $1(8.33 \%)$ \\
\hline Hemorrhage & $1(8.33 \%)$ \\
\hline Normal & $1(8.33 \%)$ \\
\hline
\end{tabular}

Table 2: Involvement of lobes in eclampsia.

\begin{tabular}{|ll|}
\hline Lobes involved & Number of patients \\
\hline Parietal & $10(83.33 \%)$ \\
\hline Occipital & $7(58.33 \%)$ \\
\hline Frontal & $4(33.33 \%)$ \\
\hline Temporal & $3(25 \%)$ \\
\hline
\end{tabular}




\section{DISCUSSION}

Preeclampsia/eclampsia is considered to be primarily a placental disorder. Both poor placentation as well as hyperplacentosis is associated with this condition ${ }^{5}$. Vasospasm which follows vasoconstriction as a result of severe hypertension is thought to cause local ischemia, arteriolar necrosis and disruptions of blood brain barrier which leads to cerebral oedema. ${ }^{6}$ It is possible that both vasoconstriction as well as forced vasodilatation causes cerebral edema. ${ }^{7}$ These are due to irregularities in the auto regulation of cerebral circulation. ${ }^{8}$

Disruption of the blood-brain barrier occurs due to both the hypertension-induced capillary damage and the immune-mediated endothelial dysfunction. This leads to extravasations of red cells and plasma proteins into perivascular space causing cerebral edema. ${ }^{9}$ Cerebral vasospasm, produced by a combination of reaction to hypertension, prostaglandin deficiency, defects in the NOS gene (coding for nitric oxide synthase) and endothelial damage, play an important role, producing ischemia and infarction in the brain tissue. .,10 $^{7}$

The impaired blood coagulation system and the abnormalities and deficiency of platelets predispose to intra-cranial bleeds. ${ }^{11}$ Thus, a varied picture of cerebral pathology showing evidences of cerebral oedema, microinfarcts, cortical petechiae and pericapillary haemorrhages is observed in the brains of patients with pre-eclampsia or eclampsia, which clinically manifest as headache, visual disturbances, confusion and seizures. Characteristic lesion locations are parietal and occipital lobes, followed by the frontal lobes, the inferior temporaloccipital junction, and the cerebellum. ${ }^{12}$

A study of 76 patients by McKinney AM et al, showed that the incidence of regions involvement was parietooccipital $98.7 \%$, temporal $68.4 \%$, thalamus $30.3 \%$, cerebellum $34.2 \%$, brainstem $18.4 \%$, and basal ganglia $11.8 \%$. The incidence of less common manifestations was enhancement $37.7 \%$, restricted diffusion $17.3 \%$, haemorrhage $17.1 \%$ and a newly described unilateral variant $2.6 \% .^{13}$

Bartynski WS et al, described vasogenic oedema in parietal or occipital regions $98 \%$, frontal lobes $68 \%$, inferior temporal lobes $40 \%$, cerebellar hemispheres $30 \%$, basal ganglia $14 \%$, brainstem $13 \%$, deep white matter $18 \%$ and splenium $10 \% .^{14}$

\section{CONCLUSION}

It is evident from study that brain stem edema was most common cerebral lesion followed by infarction and hemorrhage and parietal lobe was most common affected area. CT scan of brain can provide useful information to detect different brain lesions in eclampsia which may need specific modification in management protocol to prevent long term neurologic sequels and reduce maternal mortality and morbidity; although these parameters are not included in this study.

Hira B and Moodley $\mathrm{J}$ have shown that CT scan does change management in $27 \%$ of eclamptic mothers which is statistically significant. Early recognition of the disorder and prompt management by control of blood pressure, removal of the offending medications or treatment of associated diseases is essential to prevent irreversible brain damage.

\section{ACKNOWLEDGMENTS}

Authors would like to thank Dr. Nirmala Sharma for her guidance and help.

Funding: No funding sources

Conflict of interest: None declared

Ethical approval: Not required

\section{REFERENCES}

1. Sibai BM. Diagnosis, prevention, and management of eclampsia. Obstet Gynecol. 2005;105:402-10.

2. Lubarsky SL, Barton JR, Friedman SA, Nasreddine S, Ramadan MK, Sibai BM. Late postpartum eclampsia revisited. Obstet Gynecol. 1994;83:502-5.

3. Dutta DC. Hypertensive disorders of pregnancy. Textbook of obstetrics. 8th Edition. Jaypee Brothers Medical Publishers (P) Ltd. 2015:271

4. Schwartz RB1, Feske SK, Polak JF, DeGirolami U, Iaia A, Beckner KM et al. Preeclampsia-Eclampsia: Clinical and Neuroradiographic correlates and insights into the pathogenesis of hypertensive encephalopathy. Radiology. 2000;217(2):371-6.

5. Roberts JM, Redman CWG. Pre-eclampsia - more than. Pregnancy induced hypertension. Lancet 1993;341:1447-51.

6. Royburt M, Seidman DS, Serr DM, Mashiach S. neurologic involvement in hypertensive disease of pregnancy. Obstet Gynecol Surv. 1991;46:656-64.

7. Will AD, Lewis KL, Hinshaw DB Jr, Jordan K, Cousins LM, Hasso AN, et al. Cerebral vasoconstriction in toxaemia. Neurology. 1987;37:1555-7.

8. Strandgaard S. The lower and upper limits for autoregulation of cerebral blood flow. Stroke. 1973;4:323

9. Benedetti TJ, Quilligan EJ. Cerebral oedema in severe pregnancy- induced hypertension. Am J Obstet Gynecol. 1980;137:860.

10. Qurashi AI, Frankel MR, Ottenlips JR. Cerebral haemodynamics in pre-eclampsia and eclampsia. Arch Neurol. 1996;53:1226-31.

11. Gant NF, Daley GL, Chand S Whalley PJ, MacDonald PC. A study of angiotensin II. Pressure response throughout primigravida pregnancy. J Clin Invest. 1973;52:2682. 
12. Truwit CL, Denaro CP, Lake JR, De Marco T. MR Imaging of reversible cyclosparin $A$ induced neurotoxicity. Am J Neuroradiol. 1991;12:651-9.

13. McKinney AM, Short J, Truwit CL, McKinney ZJ, Kozak OS, Santa Guz KS et al. Posterior reversible encephalopathy syndrome: incidence of atypical regions of involvement and imaging findings. Am J Roentgenol. 2007;189:904-12.
14. Bartynski WS, Boardman JF. Distinct imaging patterns and lesion distribution in posterior reversible encephalopathy syndrome. Am J Neuroradiol. 2007;28:1320-7.

Cite this article as: Gurjar B, Rawat RP. CT scan findings in patients of eclampsia. Int J Reprod Contracept Obstet Gynecol 2017;6:3405-8. 